melonoma by MacKay; ${ }^{7}$ even without melanosoma, these microtubules suggest the diagnosis of achromatic metastases of a melanoma.

The development of such metastasis could be explained in several ways: the blood arterial tract, the retrovenous route from the cavernous sinus through the superior petrosal sinus, ${ }^{5}$ a nerve brain route from the oropharynx to the CPA; such a route could also explain the leptomeningeal carcinomatosis, which is responsible for the dissemination in the CNS via the CSF.

Clinically, the metastases are very different from the other tumours of CPA. Brackmann nevertheless emphasises that the hearing loss is invariable, rapid, associated with headache, and involvement of the last cranial nerves suggests a malignant neoplasm.

The CT scan, however, often suggests an acoustic neuroma. A petrous erosion ${ }^{148}$ or a vascular blush may confirm the diagnosis. ${ }^{8}$ In the absence of clinical evidence the nature of the lesion is often discovered at surgery or necropsy.

O DELERUE A DESTEE

Department of Neurology A, Centre Hospitalier Universitaire, HU, Lille.

Department of Neurology, CHG, Boulogne, France

Correspondence to: Professor Destee.

1 Brackmann DE, Bartels LJ. Rare tumors of the cerebello pontine angle. J Oto laryngol 1982;34:89-103.

2 Cornil L, Paillas JE, Vague J. Localisation pontocérébelleuse metastatique d'un epithelioma du cavum. Rev Neurol (Paris) 1934;67:106-11.

3 Fischer A, Marres E, Thijssen H. A tumor in the cerebellopontine angle region. An unusual
case. Clin Neurol Neurosurg 1977;80:189-94.

4 Nakada T, St John JN, Knight JN. Solitary metastasis of systemic malignant lymphoma to the cerebellopontine angle. Neuroradiology 1983;24:225-8.

5 Cohen DL, Diengdoh JV, Thomas GT, Himsworth RL. An intracranial metastasis from a PRL secreting pituitary tumor. Clinical Endocrinology 1983;18:259-64.

6 Jahrsdoefer RA, Sweet DE, Fitz-Hugh S Malignant fibrous xanthoma with metastasis to cerebellopontine angle. Arch Otolaryng 1976;102:117-20.

7 MacKay B, Avala AG. Intracisternal tubules in human melanoma cells. Ultrastruct Pathol 1980;1(1):1-6.

8 Kendall B, Symon L. Investigation of patients presenting with cerebellopontine angle syndromes. Neuroradiology 1977;13:65-84.

\section{Myasthenia gravis aggravated by pyrantel pamoate}

Pyrantel pamoate is an antihelmintic agent used worldwide. 'We report worsening of myasthenia gravis by pyrantel pamoate in one patient.

In October 1989 a 72 year old diabetic man noticed mild intermittent palpebral ptosis when watching television. He was blind in the right eye from diabetic retinopathy. In mid November of the same year, he complained of diarrhoea. A stool specimen was positive for Ascaris lumbricoides and a single $1000 \mathrm{mg}$ dose of pyrantel pamoate was taken orally with breakfast on 26 November. Several hours later he became fatigued when chewing and also when walking. The following week he could not chew meat and bread and he noticed dyspnoea. Neurological examination on 4
December showed bilateral palpebral ptosis with fatigability, limitation of abduction of both eyes and limitation of adduction of the right globe, hypophonia, weakness of neck extension and weakness of abduction of both arms.

Administration of $2 \mathrm{mg}$ of edophronium chloride reversed the ophthalmoparesis. Electrophysiological study revealed a normal area of compound muscle action potential in the right abductor digiti quinti muscle both at rest and after 15 seconds of maximal voluntary effort. Supramaximal repetitive stimulation of the right ulnar nerve at $3 \mathrm{~Hz}$ and $30 \mathrm{~Hz}$ were within normal limits.

Stimulation single fibre electromyography ${ }^{2}$ of the right extensor digitorum comunis muscle showed a mean jitter of $\mathbf{4 0} \mu$ s (upper normal limit $25 \mu \mathrm{s}^{2}$ ): $50 \%$ of insertions showing increased jitter and no blockings were found. Haematocopical and biochemical tests were normal. Antinuclear antibodies were positive at a 1/340 title with an homogeneous pattern. AntiDNA antibodies were negative. Antismooth muscle and antimitochondrial antibodies were positive at a $1 / 80$ title. CT of the thorax was normal. Antiacetylcholine receptor antibodies were not determined.

He was treated with $180 \mathrm{mg}$ day of pyridostigmine bromide without alleviation of his symptoms. There was no improvement in spite of increasing the daily dose of pyridostigmine and muscarinic symptoms appeared. Prednisone $60 \mathrm{mg}$ day was started. Two weeks later he could tolerate solid food. Dyspnoea, weakness of neck extension and weakness of the extremities disappeared, but ophthalmoparesis persisted. From February 1990 he is on alternate day prednisone, $70 \mathrm{mg}$ every other day, without neuromuscular symptoms apart from ptosis and bilateral ophthalmoparesis.

We feel that, in this patient, ingestion of pyrantel pamoate aggravated a previously existing myasthenia gravis. Pyrantel exerts its antihelmintic action by blocking the worm's neuromuscular transmission, producing a depolarising-type neuromuscular block. ${ }^{13}$ In rabbits, parenteral administration leads to paralysis and death, ${ }^{3}$ but toxic neuromuscular effects in humans have not been reported to date to our knowledge.

ENRIQUE BESCANSA
Section of Neurology
MANUEL NICOLAS
Service of Internal Medicine
CRISTINA AGUADO
Family Medicine Unit
MANUEL A TOLEDANO
Service of Clinical Neurophysiology
MONTSERRAT VINALS
Section of Neurology, Regional Hospital Reina
Sofia, Cordoba, Spain

Correspondence to: Dr Bescansa, Section of Neurology, Regional Hospital Reina Sofia, Avda Menendez Pidal s/n, 14004 Cordoba, Spain.

1 Katz M. Antihelmintics. Current concepts in the treatment of helmintic infections. Drugs 1986;32:358-71.

2 Trontelj J, Mihelin M, Stalberg E. Axona stimulation for end-plate jitter studies. Neurol Neurosurg Psychiatry 1986;49:677-85.

3 Rollo IM. Drugs used in the Chemotherapy of helmintiasis. In: Goodman Gilman A, Goodman LS, Gilman A, eds. The pharmacological basis of therapeutics, 6th ed. New York: MacMillan, 1980:1013-37.

\section{Myxopapillary ependymomas arising} from nerve roots of the spinal cord

Conventional pathogenesis suggests that myxopapillary ependymomas arise from ependymal cells lying adjacent to fibrous tissue. The large majority of myxopapillary ependymomas arise from the filum terminale where this arrangement applies. I report two cases of myxopapillary ependymomas arising from nerve roots of the cauda equina. This unusual and so far unreported origin, may be due to myxopapillary ependymomas arising directly from ependymal cells lying against the nerve roots.

Ependymomas form 2-6\% of all gliomas. Myxopapillary ependymomas belong to a distinctive subgroup of ependymoma. They are virtually restricted to the cauda equina and are thought to originate from the filum terminale and conus medullaris. Myxopapillary ependymomas form (16\%) $9 / 53$ to (21\%) 8/27 of intraspinal tumours (six and two respectively). Their restrictive origin and fibrous histology has led to the belief that the pathogenesis of myxopapillary ependymoma is related to ependymal cells lying against fibrous tissue mainly the filum terminale. ${ }^{912}$ Myxopapillary ependymomas also arise, rarely, in subcutaneous sacrococcygeal tissues, $^{34}$ the lateral ventricle, ${ }^{11}$ and the cervico-thoracic cord. ${ }^{12}$ The pathogenesis for myxopapillary ependymomas arising in such sites is less clear.

The first case was a 48 year old male with a one month history of low back ache and left leg sciatica with dragging of his left foot. There was weakness of the left ankle dorsiflexion, eversion of the left ankle and weakness of the knee on the same side. Myelogram showed complete block at spinal level lumbar 2 . The second case was a 44 year old male who had experienced low back pain for three years. There were no neurological signs. Myelogram revealed a block at spinal level thoracic 12 .

Macroscopically these were large encapsulated tumours. The myxopapillary ependymoma in case 1 arose from the first sacral root and in case 2 it arose from the second lumbar root. Treatment for both cases was excision of tumour and resection of the nerve root. Microscopically these were discrete highly vascular tumours. There was a compact arrangement of ependymal cells and fibrous tissue around cores of hyaline acellular connective tissue rich in blood vessels.

The presentation of these two tumours is similar in many ways to myxopapillary tumours arising from the filum terminale or the conus medullaris, namely low back pain with myelographic block.12 The orthodox pathogenesis for myxopapillary ependymoma is from ependymal cells lying against fibrous tissue for example the filum terminale. Other proposed theories include myxopapillary ependymoma arising from ependymal rests in extra dural locations such as the sacrococcygeal region. ${ }^{10}$ It has been observed ${ }^{7}$ that ependymal rests occur in normal children, and occur where myxopapillary ependymomas arise in the sacrococcygeal region, namely the dermis-subcutaneous junction. It may be that myxopapillary ependymomas arise in abnormal sites as a result of heterotopia, but heterotopia of tissue of the central nervous system in sites other than nasal is open to doubt. ${ }^{13}$

Others " have suggested that the presence of ependymal cells against fibrous tissue is not essential for the formation of the myxoid change seen in myxopapillary ependymomas. They suggest that this myxoid change is the result of anoxia due to vascular changes. Anoxia, however, is unlikely to be the primary cause of myxopapillary ependymomas or the changes seen within them, 